there are any primitive tribes on record who, when discovered, had not reached the stage of artistic imitation of any natural object.

On the theory above indicated, such a tribe might still be in the 'gabble' stage of speech, and, in fact, in the same stage of mental development as uneducated deaf mutes are to-day.

In their case, as was said above, and as is well known to those who are concerned with the education of deaf mute children, the deaf mute naturally expresses himself by free pantomime. The elements of meaning are not analysed into their component parts (as objects, actions, qualities, spacial relations, etc.) each represented by a separate invariable symbol, but are represented as 'events as a whole'.

Indeed, the main difficulty in the education of the deaf mute arises from the fact that he cannot-by Nature-understand what a word is, and has no gestures corresponding to words. He can perfectly appreciate events and invent for himself a pantomime which will bring the same event to the consciousness of his fellow deaf mutes, and this pantomime is so natural and expressive that (as is well known) the deaf mutes of all nations have no difficulty in communicating with one another.

The importance of a verbal type of gesture language (with separate, invariable signs for each element of meaning) lies in the fact that with this power of separate symbolism comes the power of making new syntheses, and that this power may have been almost wholly lacking before the necessary analytical and symbolic powers were evolved. Man's 'inventive' power would then have been on the same plane as that of the animal world.

It is evident that words, depending on mouth gesture, associated with hand gesture of a standardized (analytic) type, could only at first express concrete ideas ; namely, such objects, actions, spacial relations, qualities, etc., as could be symbolized by bodily attitude or movement-posture or gesture.

The faculty of symbolizing abstract ideas depended entirely on the use of man's 'poetic' faculty, especially the faculty of seeing analogues between abstract and concrete, as, on our hypothesis, he had seen the analogy between a curiously shaped stone and a bird or animal.

Thus, to the Red Indian, joy was sunshine (in) heart; sunshine and heart are both easy ideas to symbolize in signs. So joy can also be symbolized. Similarly :

$$
\begin{aligned}
& \text { sorrow was heart on the ground } \\
& \text { ambition , } \\
& \text { truth } \text { man push rise } \\
& \text { false ", (the) straight trail } \\
& \text { mean ", } \\
& \text { luck speak with) two tongues } \\
& \quad \text { turn up (in the Indian gambling } \\
& \quad \text { stick game). }
\end{aligned}
$$

It is entirely on this principle that all words for abstract ideas have been formed throughout the world. Thus (Greek) metaphor is, literally, to carry across, that is, from the concrete to the abstract.

Or take the idea of fear. This is commonly sym. bolized by the use of a concrete symbol meaning to shrink, or draw back (as in the Red Indian hand gesture for fear) or by reference to one of the concrete effects of fear, trembling, paralysis or the like, or to some concrete action calculated to cause fear.

Thus, in archaic Chinese, out of 14 separate words meaning fear (according to Karlgren ${ }^{1}$ ), 6 are produced by what are in fact drawing-back actions of the tongue, or lips and tongue (with or without a preliminary forward motion)-KING, LAK, KUNG, SUK, wEI, T'IEUT; 2 are produced by mouth gestures related to shivering-LIĚT, LIEM ; 4 are related to concrete gestures meaning to bind, grip or seize, scatter or strike-L wO, P'A', P'UO', D'ÂN-and only 2-KI, G'IU-which might mean to drop at the back, and to pour out, respectively-are not obviously related to any concrete action connected with fear.

Such instances of the developments of abstract signs (or words) by the poetical use of concrete symbols could be multiplied almost indefinitely. The few which have been given may suffice to show how important the poetic instinct in man has been in providing a ready means for expressing abstract ideas by the 'metaphorical' use of concrete symbols. It is probably true to say that but for the poetic instinct man might for ever have been limited to the narrow field of concrete ideas.

But what really distinguished man from the higher apes was that he had become a symbolizing animal, and that symbolism was the mother of invention.

t "Analytic Dictionary of Chinese."

\title{
Presentation of the Kelvin Medal to Sir J. J. Thomson
}

\begin{abstract}
THE Kelvin Medal, which was founded to commemorate the work of Lord Kelvin, is awarded triennially by a committee in London consisting of the presidents of eight of the leading engineering institutions of Great Britain, after consideration of recommendations received from similar bodies in all parts of the world. Sir J. J. Thomson was selected as the recipient of the award for 1938 (see NATURE, May 7, p. 825) and the presentation was made on May 3 in the Great Hall of the Institution of Civil Engineers by Lord Rayleigh on behalf of the Kelvin Medal Award Committee. Lord Rayleigh's address is printed below.
\end{abstract}

It is more in accordance with the natural order of things that a master should present a prize to a pupil than that a pupil should present one to a master. Those who stood in the relation of master to the man that we are met to honour to-day (and I am proud to remember that my own father was among them) have passed into silence : and the duty falls to one of a younger generation.

Sir J. J. Thomson tells us in his "Recollections and Reflexions" that he was originally intended for the career of an engineer. Fate had apparently decided otherwise; but the most direct route is not neces. sarily the only one. In spite of this apparent renunciation, he is here to-day to receive the Kelvin Medal, perhaps the highest distinction which the engineering profession has to confer. It is a tribute to the breadth of view of the profession that this should be so. When the Faraday centenary was in 
course of celebration, it occurred, I believe, to some influential members of the Institution of Electrical Engineers that the terms on which their membership was granted would perhaps have excluded Faraday himself. We may look on the present award as a healthy reaction from that state of things. It shows that the bodies making the award are animated by no narrow spirit of professionalism. The doctors learnt much from Pasteur, though he was not a member of their profession. Similarly, the engineers have learnt much from J. J. Thomson.

Let me remind you of some of it ; and let me say that I am not speaking from book knowledge, still less from hearsay. I was working in the Cavendish Laboratory when many of the things were done, and $I$ saw them in progress. The professor was very much the reverse of a mystery man-he told us freely of his half-formed ideas, and even allowed us to argue with him about them. For example, he was much exercised about the nature of cathode rays, the properties of which had been so well described by Hittorf, Crookes, Goldstein, and Lenard. Were they a stream of electrified particles, or were they not? At first the only fact with a really clear bearing on this question was the magnetic deflection. Thomson was one of those who saw most clearly the full strength of this argument. But he saw that there ought to be an electrostatic deflection as well, when a transverse electromotive force was applied; and that did not seem to happen. Why not? Thomson wondered whether the electromotive force really was being fairly applied. He found that the cathode rays made the residual gas in the vessel very conductive. The result of this was that all the applied voltage was ineffectively dropped on the space near the transverse electrodes where the rays were not. The remedy for this was to have as little gas as possible. High vacua were not so easily made then as they are now. However, the difficulty was overcome, and the transverse deflection observed.

What has all this got to do with engineering? Well, take the cathode ray oscillograph, the tool of the electrical engineer for dealing with all problems concerning rapid surges of current and potential. What is this but a glorified edition of the apparatus with which Thomson observed the electrostatic deflection of cathode rays, and discovered the electron? Again, take television. Does not cathode ray television depend on the use of electrostatic deflection to cause the cathode beam to scan the picture? If we did not know that the cathode rays were charged particles, should we have known how to retard them by longitudinal electric forces, so as to modify the energy, and produce the light and shade of the picture?

I have taken a fow direct examples coming immediately from Thomson's own researches. But his services to engineering by no means end with them. There can be little doubt that his early writings on electric waves and oscillations were a main source of inspiration to those who were concerned with the development of wireless and of high-frequency electrical engineering generally. Before he turned his attention to electric discharge phenomena, there was so far as I can recall no systematic treatment of the subject, and when it came to the development of the three electrode valve, and the various forms of electric discharge lamps which now light our streets, it was to Thomson's writings that the inventor turned for guidance.

\section{William Herbert and Amaryllis Culture}

"H ERBERT bridges the gap not only between Ray and Darwin but also between Kölreuter and Mendel," writes Dr. C. D. Darlington in "Herbertia", the year-book of the American Amaryllis Society for $1937^{1}$. The Hon. and Rev. William Herbert was for thirty-three years rector of Spofforth in Yorkshire. He published, in 1837, a volume on the Amaryllidacer, which must still be consulted by any serious student of the genus, and fully warrants the Society's choice of the title "Herbertia" for its year-book. An addendum to Herbert's volume of 1837, entitled "On Crosses and Hybrid Intermixtures in Vegetables" was, moreover, a classic which fully justifies Dr. Darlington's estimate. The text appears in the 1937 "Herbertia" and should be read for its historical value as a portrayal of early work on conscious hybridization.

Few year-books achieve such monographic treatment as "Herbertia". Full consideration is given to the Society's affairs and regional activities, but there are also numerous original articles, and an intensive system of review paragraphs. The main contribution in the section on description and phylogeny is by Spencer Savage, and concerns a manuscript by the younger Linnæus dealing with certain genera now included in the Amaryllidaceæ. W. S. Flory and

${ }^{1}$ From the Editor, Dr. Hamilton P. Traub, Mira Flores, Orlando, Florida, U.S.A. Pp. 272. Oct. 1937.
S. H. Yarnell contribute a comprehensive review of chromosome numbers in the Hemerocallideæ, Alstromeriales and Amaryllidales, whilst Friedrich Meyer describes a new daffodil mutation, Narcissus schizo. coronatus. Many other accounts of particular crosses also appear.

The section on the physiology of reproduction contains papers on the effect of growth substances on Hippeastrum, Hemerocallis and Alstromeria by Dr. Hamilton P. Traub, the editor, who also writes on new methods of propagating Hemerocallis. The tender crown tips are severed and then cut longitudinally into halves or quarters, which are capable of rooting in a sandy medium. Mr. Wyndham Hayward, secretary to the Society, has also shown that the portion of rhizome remaining after the crown has been severed can be induced to form four or five shoots, which can later be propagated as separate plants. H. H. Hume and J. V. Watkins have a paper on propagation of Zephyranthes by various methods of cutting the root plate of the bulb.

Very numerous papers on amaryllid culture appear, and a small section on harvesting, storage and forcing is to be expanded to greater dimensions next year. No narrow national limits are interpreted into the Society's title, and one cannot but be grateful for its international scope and appeal. 